\title{
An Investigation and Countermeasures on the Cultural Adaptation of African Students in China
}

\author{
Xinxin Jin (Corresponding author) \\ School of Liberal Arts, Jiangsu University \\ PO Box 212013, Zhenjiang, Jiangsu, China \\ Tel: 86-181-5625-4139Ｅ-mail: 1048186766@qq.com \\ Rabnawaz Khan \\ Dept. of Finance and Economics, Jiangsu University \\ PO Box 212013, Zhenjiang, Jiangsu, China \\ Tel: 86-188-5286-8707Ｅ-mail: khan.rab@stmail.ujs.edu.cn
}

\author{
Wu Xiao Feng \\ School of Liberal Arts, Jiangsu University \\ PO Box 212013, Zhenjiang, Jiangsu, China \\ Tel: 86-158-0528-1963Ｅ-mail:6168395@163.com
}

Received: November 12, 2019 Accepted: November 28, 2019 Published: December 5, 2019

doi:10.5296/ijld.v9i4.16082

URL: https://doi.org/10.5296/ijld.v9i4.16082

\begin{abstract}
Culture adaption is based on norms, customs and language, which entails moving from different classes and voluntary immigration. This qualitative and quantitative research paper is exploring the new ideas and fondness of interchange personalities of students, who are studying in different universities and in different cities of Jiangsu province. The empirical analysis of this study is investigated that those African students who have a well-educated and oriented in their own specialization but still in case of language they have faced some tactical challenges with different race and nations. Furthermore, the African students not directly integrate with Chinese culture comparatively other nations of students. However, some proposals will be offered to help African students' living and learning. Additionally, to develop the relationship by state with new ideas and to improve the business policies from African countries.
\end{abstract}

Keywords: African students, cultural adaptation, Republic of China, customs and language 


\section{Introduction}

Cross-cultural as a term of anthropology initially, Kalervo Oberg was a pioneering scholar of cross-cultural experience and pointed that the process of cultural-adapting can be considered as a feeling which start from positive and attracted by the new environment to turn into the emotion of shock, hostility, fear and so on (Furnham, 1986). There are different definitions and understandings. Cross-cultural adaptation has been defined by Kim as the dynamic process which happened when the individuals migrate to a new, unfamiliar, environment, and maintain relatively stable and harmonious relationship with those environment (Kim, 2001). Acculturation is a process of cultural psychological change when two or more cultural groups and individuals contact (Berry, 2005). And it refers the abilities to do daily activities by learning the local language and social culture, by communicating with the local people (Astrid Vanessa Sarmientoa, 2019). Searle and Ward (1990) concludes that Cross-cultural adaptation is a process of psychological and sociocultural adjustment.

The prior research approaches to adapt intercultural and also according to John W. Berry and Chris R. Glass that different individuals and groups have different strategies to undergo acculturation which consist of two components $1^{\text {st }}$ individual attitudes and $2^{\text {nd }}$ daily behaviors.(Berry, 2005). The different international students' adaptation varies including recreation participation, intercultural friendship, and adaptation to college in the U.S. Then finds that it is effective to participate in recreation and leisure activities to format intercultural friendship and adapt to college life (Glass, Gómez, \& Urzua, 2014).

As well, some researches revealed the factors affecting cross-cultural adaptability and it is only a single factor determines cultural-adaptation process, but affected by many aspects which can accelerate or decelerate that process (YY, 2003). It shows that self-construal, English language confidence(linguistic and communication skill) are the most important factors of cultural adaptation (Yang, Noels, \& Saumure, 2006). Miglietta and Tartaglia concludes that linguistic competence, social circles, length of stay in the new culture, prior overseas experience, students' expectations of China and so on will influence the degree of satisfaction of different environment(Miglietta \& Tartaglia, 2009). Furthermore, the institutes and the social networks of students have a large influence on how international students adjust (Rienties et al., 2012).

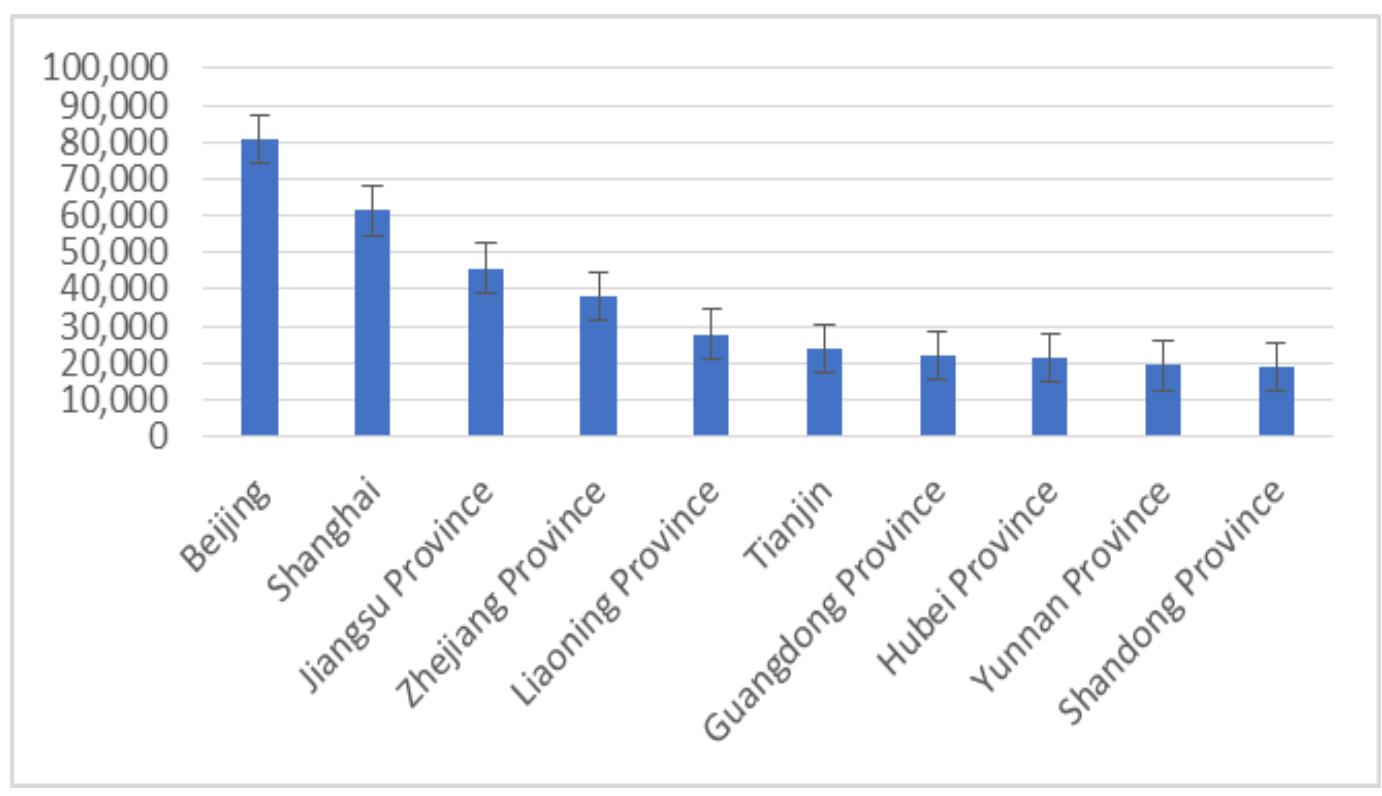

Figure 1. International students in different areas 
Worldwide, China has become the fifth largest country to enroll international students (Hvistendahl, 2008). According to the Statistics from Ministry of Education (2018), Figure 1 indicated that there were 492,185 foreign students from 196 countries and arias studying in different colleges and universities. The total number of African students was 81,562, accounting for $16.57 \%$ which is second only to Asian students. Likewise, there are different student in china in different provinces, more than 80,000 students only in Beijing. There is strong interaction of social network of foreign student in China different universities. After that Asian students, African capture the study market with $17 \%$ comparatively $27.64 \%$ from the Asian students. Which is not influence on international market of students also the promote the business resources with new and dynamic way under the rule regulation of China policies.

(Bo, 2015) intricate the close international relations between China and Africa, and note that due to the relatively large cultural differences, African students don't have the similar experiences to Asian students, even more difficulties. Therefore, it is necessary to do investigation and countermeasures on African students' ability of culture adaptation.

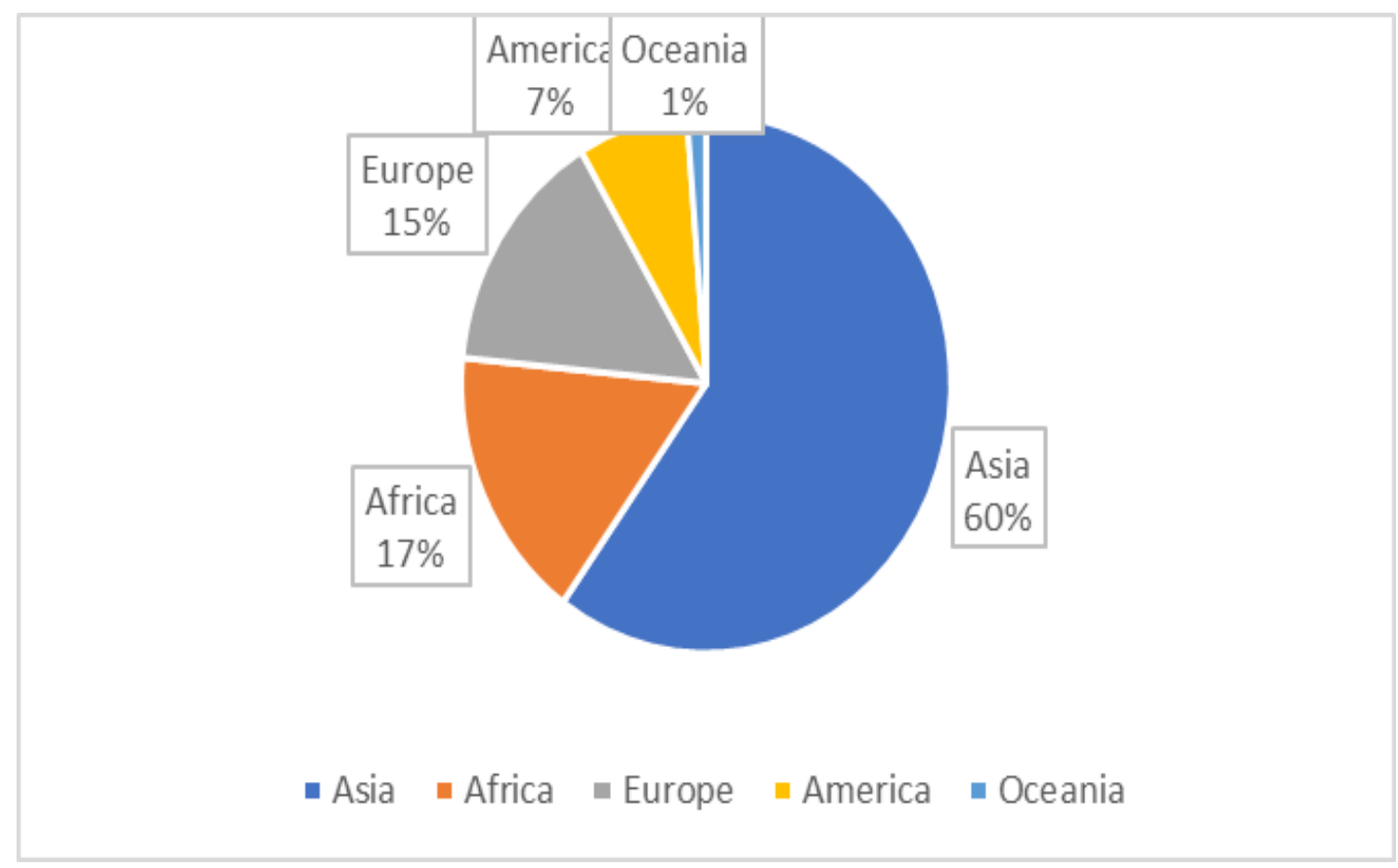

Figure 2. International students by contents

According to prior research study the western countries students indicated for cross culture and intellectual relationship. The real gap of research is explored by western theories and their behavior change but not indicate the specify race and culture. Figure 2. Furthermore, the internal studies of Chinese are analyzed by cross-cultural adaptation without in-depth investigation, psychology of students and social communication. However, the main theme of this study to answer the following questions: (a) To what issues the African students are facing in the cross-cultural adaptation in China (university study; social communication) and (b) What are the main influencing factors for African student to adjust themselves to new inter-culture? Finally, the study also aims to propose some suggestions to African students, university management and Chinese government to develop Cross-cultural adaptability. 


\section{Literature Review}

\subsection{Concepts of Cross-Cultural Adaptation}

Acculturation means some special phenomena which caused when groups or individuals with different cultures encounter, subsequently, one of the group and individual make changes of their original culture (Redfield, 1936). From the perspective of group level and individual level, John W. Berr indicates that "it involves changes in social structures and institutions and in cultural practices and changes in a person's behavioral repertoire."

Cross-cultural adaption has become a hot topic of researches abroad. There are a great deal of the terms to describe the cross-cultural adaption, such as acculturation, adjustment, assimilation and culture shock even more inclusive and broad term used by Kim (Penga et al., 2019). Cross-cultural Adaptation has been defined as a dynamic process in which residents gradually adjust, accept, adapt and integrate into the host culture. The individuals and groups find that themselves straddled between two worlds and in the new circumstance that their previously held beliefs, taken-for-granted assumptions are totally different (Kim, 2012).

\subsection{Cross-Cultural Adaptation of Foreign Students in China}

The research of cross-cultural adaptation in China started rather late, and most of them are based on foreign correlation theories and Chinese language class, but more empirical studies, including the aspects influencing foreign students to adapt to Chinese culture, how foreign students will overcome culture shock. Zhang (张静园, 1998), discussed psychological adaptation of international students and not categorized regional effects and race adoption of foreign students (孙乐岑, 2009). Furthermore, comparatively from other prior research studies this research paper investigate the Foreign students and specially to target African, and then divides the acculturation into social-adaptation, mental adaptation and cultural-adaptation. According to Searle and Ward' cross-cultural adaptation theory, the study combined qualitative and quantitative method which revealed the degree and regularity of sociocultural adaptation. L.noted that it is more easily for Asian students to adapted to different cultural than African students. There is a great potential of social network sites to international students cross-cultural adaptation (Kong \& Khan, 2019; Wang, 2015).

\section{Methods}

The third section is discussed about the data collection and sample selection; variables of research and hypothesis test. The basic aim of this current research paper to taking feedback by the questioning and how about the data were collected; what type of sampling methods is used and how the variables are measured by statistically tools. The systematic procedure of hypothesis testing is also discussed in this section.

\subsection{Data Collection and Sample Selection}

In this study, the primary data is taken from the employees. According to Samouel and Page (2017) primary data is that data which is directly collected for the research study. In other words, the data is collected from direct sources. This study employed qualitative and quantitative based research design to capture the trend of individual questionnaire by African foreign students. The research data has taken 150 sample size from the 180 number of populations. The primary data have been conducted in three different universities by 17 number of questionnaires. The model specification has been designed according to above objectives and it consisted of selecting an appropriate functional form for the model and choosing which variables to include in individual questionnaire which is close ended questions in five strategic ratings. Initial data were conducted from the pilot study and after proving rating data were conducted from African students by different states. 
This study was conducted from universities students survey in the period of 2019. The study was based on Jiangsu province of China. The research study focused on whole-population sampling methods, the Sample size of the study was 150 from a population and $83.33 \%$ of the results have been collected from the survey. We selected African countries students in different grading and education level and generated information regarding their education and gender individually. Additionally, the separate interviews were designed to allow for a deep investigation and comparison between both respondents' answers to explore the possible hypothesis effects on students by different questionnaire and with certain dimensions' results has been recorded by SPSS software. Furthermore, the surveyor has not conduct data much more information directly from the community of African students. The interview conducted individually by choice and not directly focus the skin issues by different states.

During conducting data researcher has already informed to respondent's detail of questionnaire. The current research paper also held the security and privacy issues of all that disrupted information and the detail which were collected directly or indirectly and also taking confidence of respondents regarding the information. Second the privacy has insured and informed about the consent was given individually for the better analysis.

Each respondent has received a questionnaire from the surveyor and within 15 to 20 minutes' mark and circle closet review on the questionnaire in the portion of dichotomous or two-point questions and 5-Points Likert scale. Initial data have been manipulated in excel sheet and then export data in "SPSS" software.

\section{Results}

Researcher has taken the analysis process of 150 samples individuals, after conducting data manipulation formulates research design according to hypothesis. The questionnaires design and codes of each answer given help in manipulation of data by a Likert scale. The coding procedure has initially finalized raw data in excel sheet and then it transferred to SPSS and list directly recorded in to SPSS sheet. The SPSS is the most common software as for analysis and is providing statistically techniques in manipulation of data. The reliability of data has also computed with individual parameters.(Yushang, 2018)

Initially the data are manipulated in the form of excel sheets with prescribed replies and comments. In $2^{\text {nd }}$ stage 150 samples of data were simply entered and manipulate by the individual questionnaire in SPSS sheets as for further analysis. The frequency distribution techniques analyzed by variance and the symmetric distribution of each individual also has to manipulate the result ethnicity and reliability of variables.

This research paper questionnaire is directly collected from respondents and analyzed according to the hypothesis of the research. Initially sort-out descriptive information individually on African students. This research study also has conducted material of research in during interviews like observations, pages, notes and official papers. The result of research has been analyzed by different statistical tool, like, regression, correlation and individual question analysis.

\subsection{Test Used in Research}

First step of research based on demographic view of Respondents age, education by different scale. With the statistically tools, researcher has conducted central tendency mean and standard deviation individually. Check reliability analysis by individually with analysis of parameters, conducted correlation and cross tabulation use for proving variability of analysis in each individual of 150 samples. 


\subsection{Correlation}

Correlation test shows consistency relationship with foreign students' adaption of China universities regarding Chinese language, the attitude of Chinese people and students and local people, the public policy and university management according to above hypothesis of research individually. The correlation technique ranges from -1 to +1 in which represent the strongest relationship between variables with the nearest value of +1 . The level of student's education was divided into four level, $\mathrm{PhD}$, Master, Bachelor, and language students. Fig 3-4 is indicated $64.7 \%$ male and $35.3 \%$ female has recorded their different view by 17 questionnaires (Table 1) with $62.7 \%$ of Bachelor students (Table 2).

Table 1. Q1

\begin{tabular}{lllll}
\hline \multirow{4}{*}{ Frequency } & Percent & Valid Percent & Cumulative Percent \\
\hline \multirow{4}{*}{ Valid } & Strongly disagree & 36 & 24.0 & 24.0 \\
& Disagree & 42 & 28.0 & 28.0 \\
& Uncertain or not applicable & 5 & 3.3 & 3.3 \\
& Agree & 54 & 36.0 & 36.0 \\
& Strongly agree & 13 & 8.7 & 8.7 \\
& Total & 150 & 100.0 & 100.0 \\
\hline
\end{tabular}

Table 1 is indicated the highest frequency of Likert scale with $36 \%$ results. The accommodation status in overall Chinese university is well equipped and managed, $8.7 \%$ responded strongly agree with satisfaction level of accommodation. Figure 3.

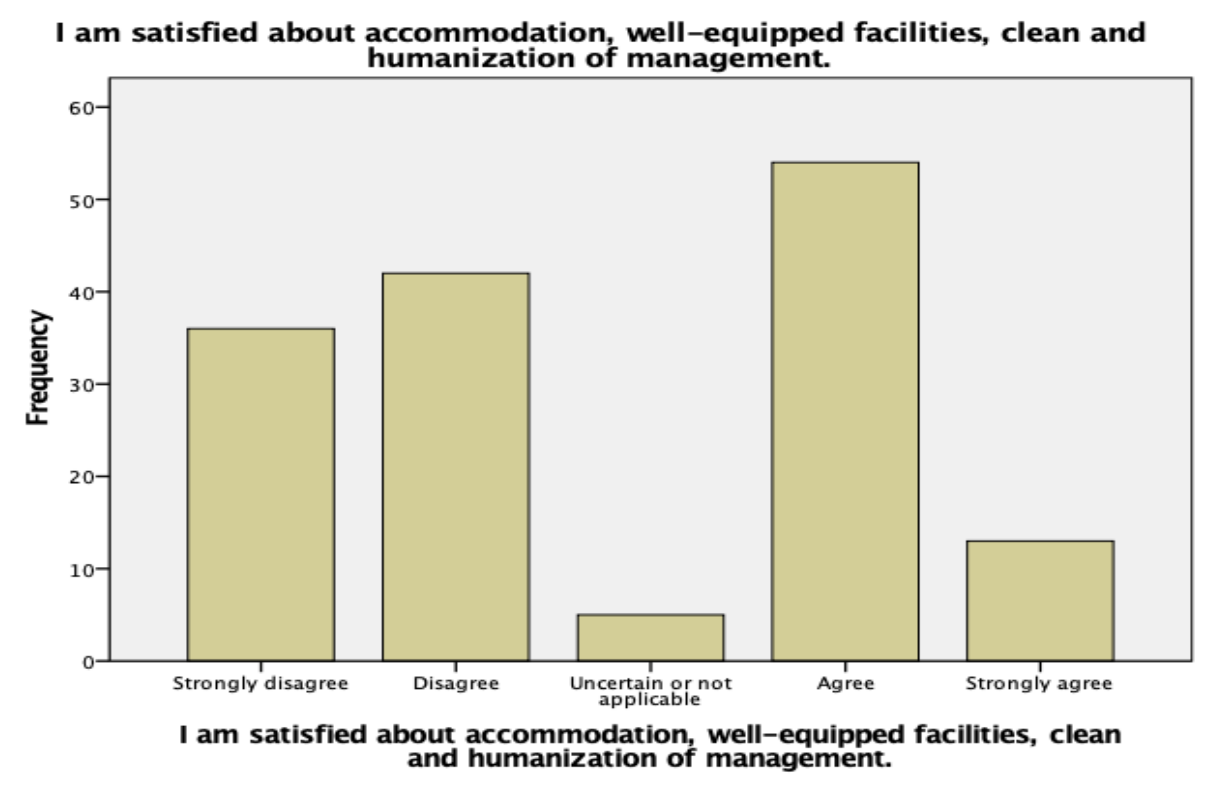

Figure 3. Respondent review of question 1 
Table 2. Question 2 respond

\begin{tabular}{lllll}
\hline \multirow{2}{*}{ Frequency } & Percent & Valid Percent & Cumulative Percent \\
\hline \multirow{4}{*}{ Valid } & Strongly disagree & 52 & 34.7 & 34.7 \\
& Disagree & 24 & 16.0 & 16.0 \\
& Uncertain or not applicable & 11 & 7.3 & 7.3 \\
& Agree & 25 & 16.7 & 16.7 \\
& Strongly agree & 38 & 25.3 & 25.3 \\
Total & 150 & 100.0 & 100.0 \\
\hline
\end{tabular}

Table 2 is indicated the results of satisfaction regarding comfortability, due to cause of different nationalities might some students have truly faced problems in case of privacy but probably universities provide accommodation on same nations students. The obtained results are showed that $16.7 \%$ students are not satisfy from others and need separation for cause of privacy. $25.3 \%$ respondent are strongly agreeing and feel not comfortable with same groups of students and friends. Figure 4.

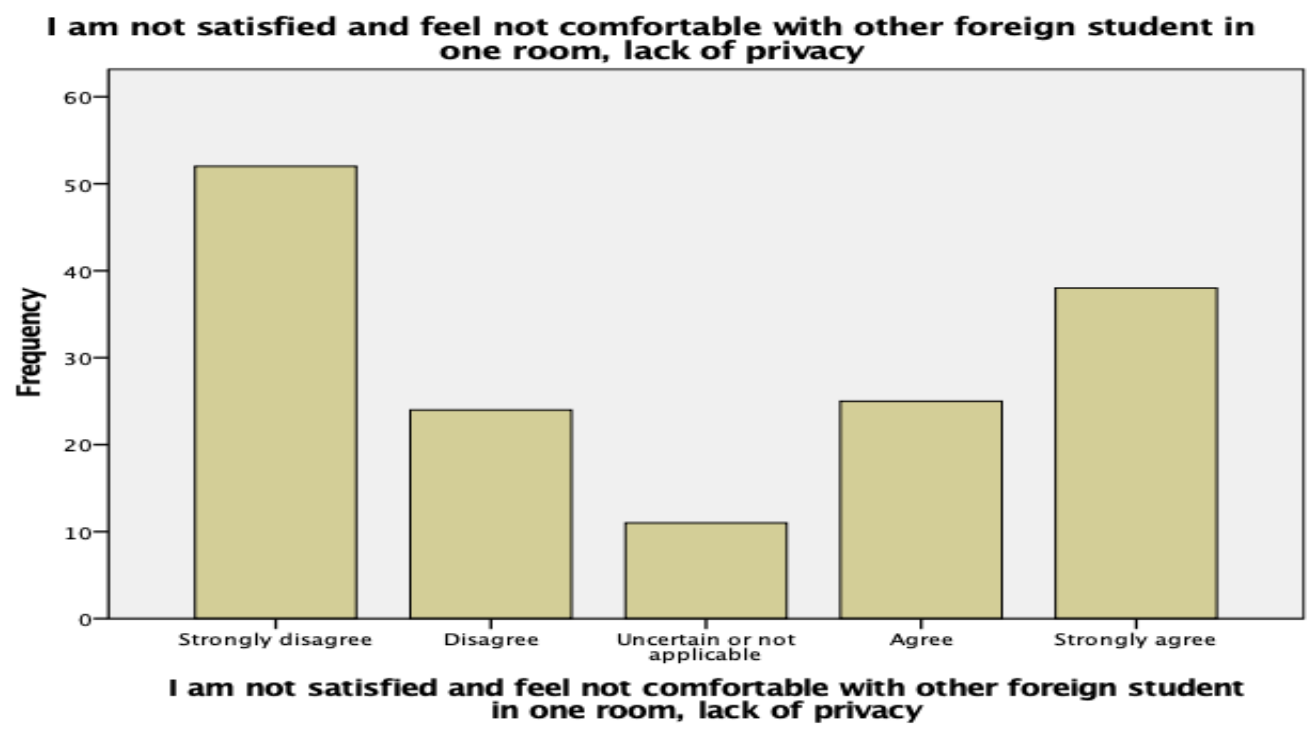

Figure 4. Respondent review of question 2

Furthermore, that there is no huge difference related the satisfaction of university accommodation, and further detail through interview, it found that different universities' students have different stratification level and university accommodation might limited for all nations students. 
Table 3. Respondent view in question 12

\begin{tabular}{lllll}
\hline \multirow{4}{*}{ Frequency } & Percent & Valid Percent & Cumulative Percent \\
\hline \multirow{4}{*}{ Valid } & Strongly disagree & 2 & 1.3 & 1.3 \\
& Disagree & 3 & 2.0 & 2.0 \\
& Uncertain or not applicable & 14 & 9.3 & 9.3 \\
& Agree & 46 & 30.7 & 30.7 \\
& Strongly agree & 85 & 56.7 & 56.7 \\
& Total & 150 & 100.0 & 100.0 \\
\hline
\end{tabular}

Table 3 is indicated the network of buying by online market. The China is one of popular country of online shopping and it provide the huge platform to all nation and international people to buy online products on cheap rates especially in Taobao and Waimai. During interview the respondent are strongly agree with $56.7 \%$ from the online shopping and it is providing them very suitable on door service without wasting time. Furthermore, students

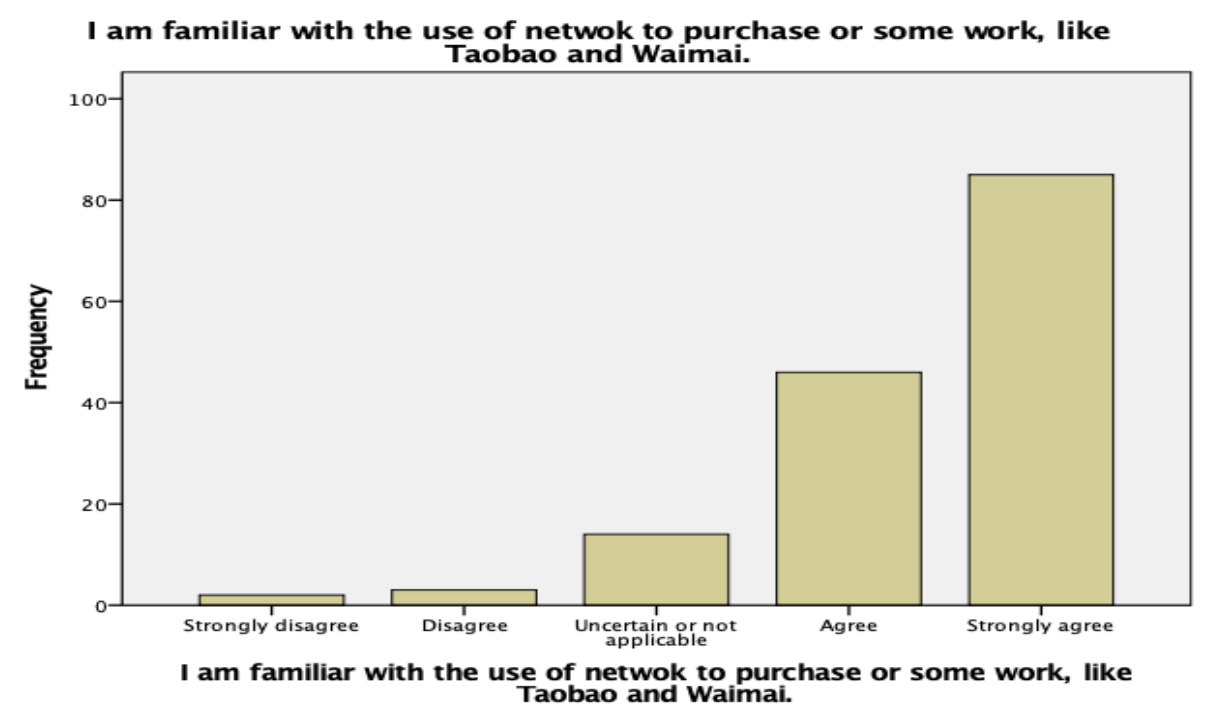

Figure 5. Respondent view in questions 12

Know how to use APP to make life more convenient, from the above statistics, it indicates that foreign student has a good adaption on living conditions generally (Figure 5).

Table 4. Respondent view in question 3

\begin{tabular}{lllll}
\hline & Frequency & Percent & Valid Percent & Cumulative Percent \\
\hline Valid & Uncertain or not applicable & 1 & .7 & .7 \\
& Agree & 37 & 24.7 & 24.7 \\
Strongly agree & 112 & 74.7 & 74.7 \\
Total & 150 & 100.0 & 100.0 \\
\hline
\end{tabular}


Table 4 is indicated the level of Chinese language classes and respondent review is shows $74.7 \%$ validity of strongly agree students, whose come from different regions and countries. The China is only of famous country who hold and command on his own language officially so therefore all foreigner students have faced bid problem in language barrier so the level of

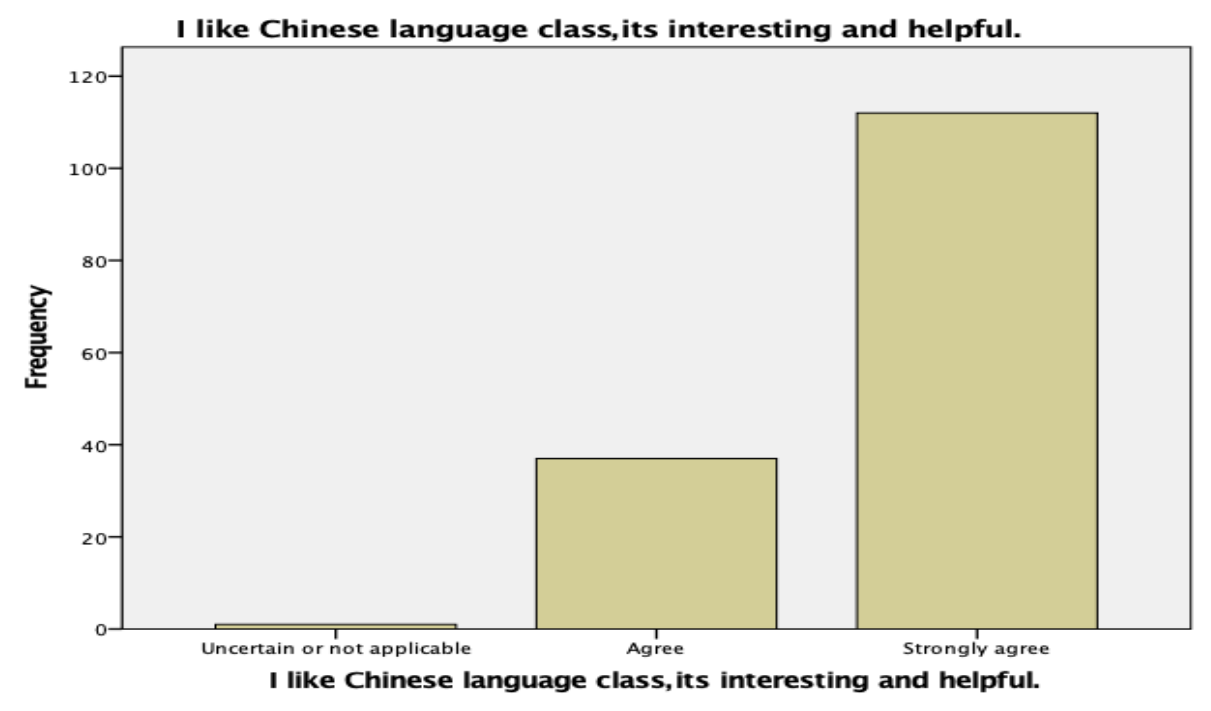

Figure 6. Respondent view in question 3

Language competency is one of important tool to develop relation and convey message. Furthermore, in this question the surveyor has not received any negative command and overall students are agree that the Chinese language is one of impotent tool of communication from Chines. Figure 6.

Table 5. Respondent view of question 4

\begin{tabular}{|c|c|c|c|c|}
\hline & Frequency & Percent & Valid Percent & Cumulative Percent \\
\hline \multirow{6}{*}{ Valid } & Strongly disagree & 3 & 2.0 & 2.0 \\
\hline & Disagree & 17 & 11.3 & 11.3 \\
\hline & Uncertain or not applicable & 19 & 12.7 & 12.7 \\
\hline & Agree & 73 & 48.7 & 48.7 \\
\hline & Strongly agree & 38 & 25.3 & 25.3 \\
\hline & Total & 150 & 100.0 & 100.0 \\
\hline
\end{tabular}

Table 5 is indicated self-stress level and physiological pressure of African students in China cause of different culture and ethnicity. In this question specify Chinese gathering for practice language so therefore lots of student's activities professionally is arranged by overseas 


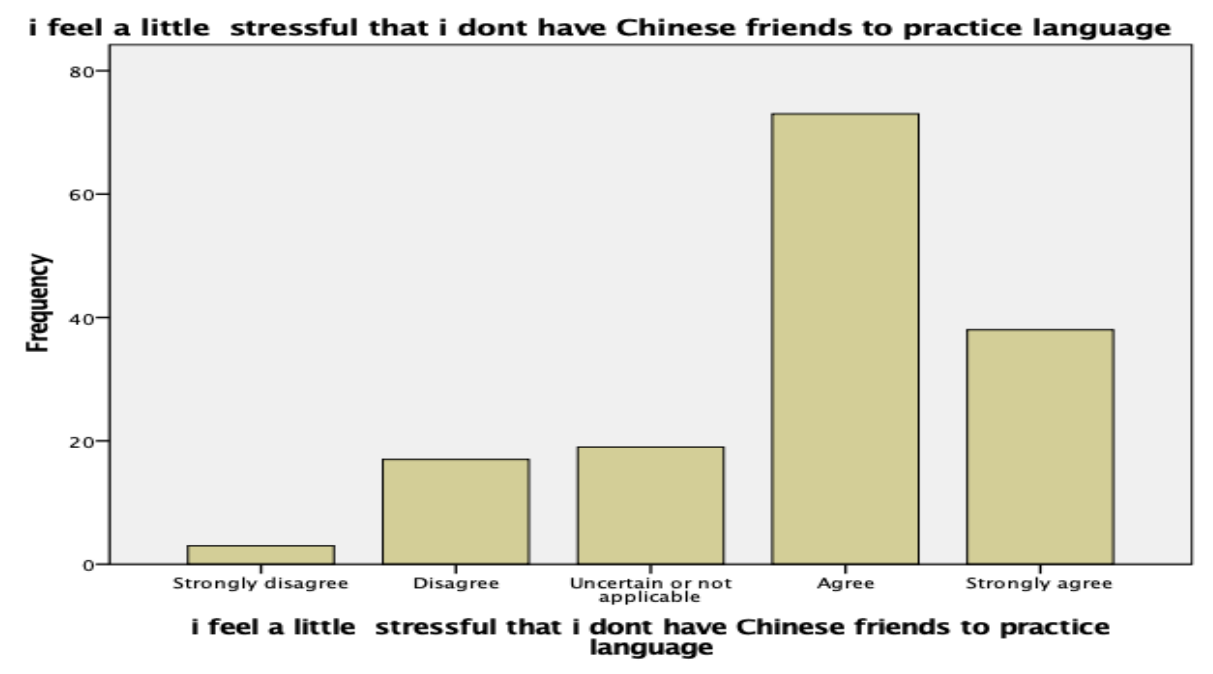

Figure 7. Respondent view of question 4

Department and involve to students with Chinese students for promoting Chinese language. The obtained results also identify the $48.7 \%$ highest level of Agree students, who satisfy from the cross-culture communication and group activities. Figure 7

Table 6. Respondent view of question 6

\begin{tabular}{|c|c|c|c|c|}
\hline & Frequency & Percent & Valid Percent & Cumulative Percent \\
\hline \multirow{5}{*}{ Valid } & Disagree & 7 & 4.7 & 4.7 \\
\hline & Uncertain or not applicable & 38 & 25.3 & 25.3 \\
\hline & Agree & 26 & 17.3 & 17.3 \\
\hline & Strongly agree & 79 & 52.7 & 52.7 \\
\hline & Total & 150 & 100.0 & 100.0 \\
\hline
\end{tabular}

Table 6 is indicated interaction of the Chines friends with foreigners because only culture and community diversify the relationship between two different nations. 


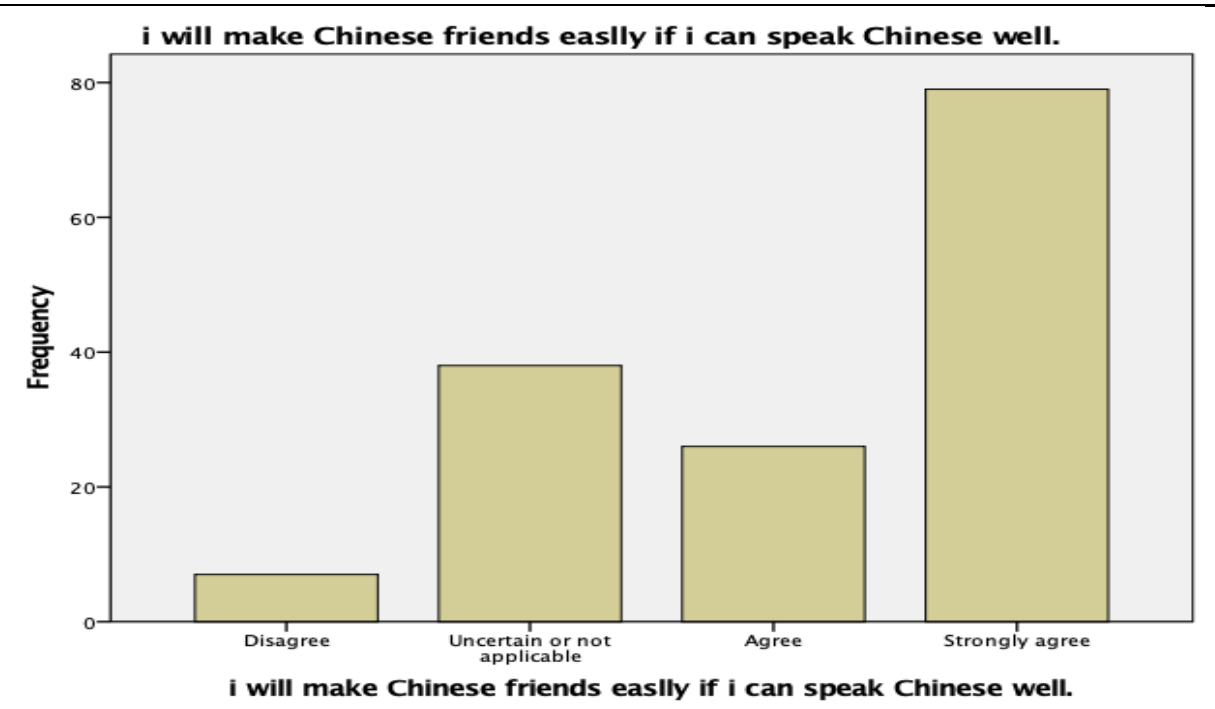

Figure 8. Respondent view of question 04

The obtained results show $52.7 \%$ validity of strongly agree students who need to make friends and would like to communicate with the Chinese students. Figure 8

Table 7. Respondent view of question 15

\begin{tabular}{|c|c|c|c|c|}
\hline & Frequency & Percent & Valid Percent & Cumulative Percent \\
\hline \multirow{6}{*}{ Valid } & Strongly disagree & 20 & 13.3 & 13.3 \\
\hline & Disagree & 14 & 9.3 & 9.3 \\
\hline & Uncertain or not applicable & 13 & 8.7 & 8.7 \\
\hline & Agree & 17 & 11.3 & 11.3 \\
\hline & Strongly agree & 86 & 57.3 & 57.3 \\
\hline & Total & 150 & 100.0 & 100.0 \\
\hline
\end{tabular}

Table 7 is specified the different universities overseas policies regarding interaction of language and communication in-between foreign and local students. The obtained results are indicated $57.3 \%$ student's response, whose totally agree that different universities are not providing much more interaction community for promoting the Chinese language. 
The inablity to communicate effectively with Chinese people brings lots of

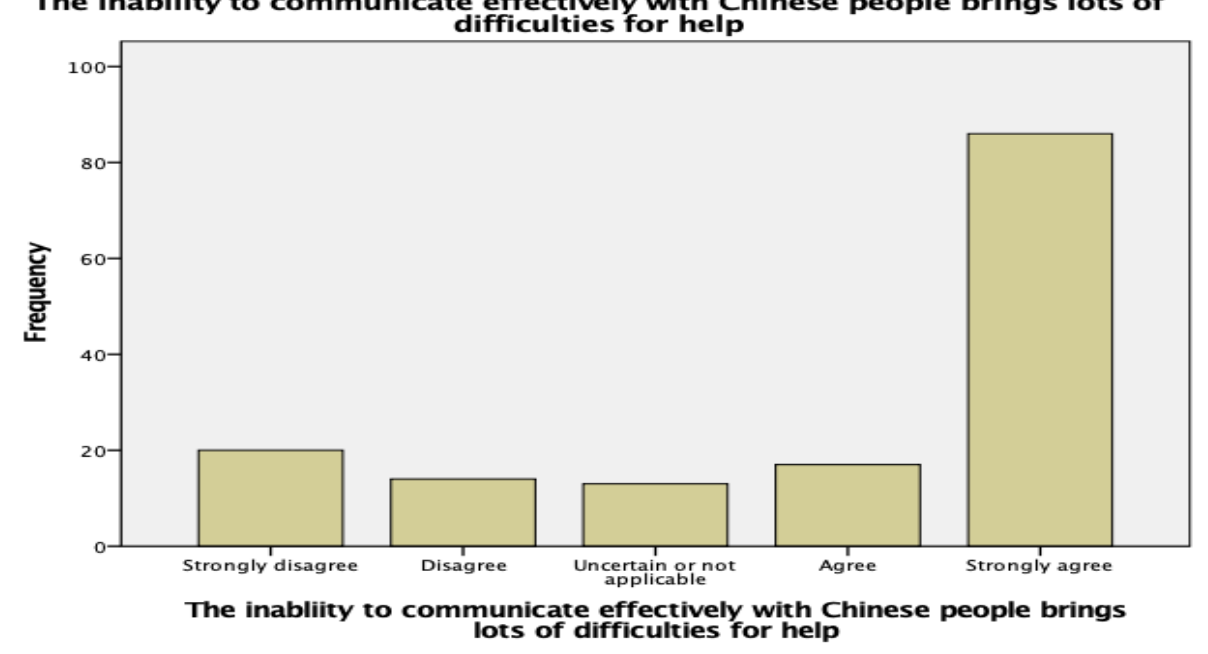

Figure 9. Respondent view of question 15

As shown in Tables 4-7, more than 90\% African students are quite satisfied with Chinese language classes, which shows the Chinese teachers' teaching skills and level became better and better, it will be more helpful for students to adapt to Chinese life well. 70\% students think that learning Chinese language bring stress, especially, there are no Chinese friends to talk. $70 \%$ students agree that Language plays an important role in making friends.

Table 8. Respondent view of question 8

\begin{tabular}{lllll}
\hline \multirow{2}{*}{ Frequency } & Percent & Valid Percent & Cumulative Percent \\
\hline Strongly disagree & 3 & 2.0 & 2.0 \\
Disagree & 2 & 1.3 & 1.3 \\
\multirow{2}{*}{ Valid } & Uncertain or not applicable & 3 & 2.0 & 2.0 \\
\cline { 2 - 3 } & Agree & 74 & 49.3 & 49.3 \\
& Strongly agree & 68 & 45.3 & 45.3 \\
& Total & 150 & 100.0 & 100.0 \\
\hline
\end{tabular}

68.6\% students consider language Community ability is a barrier to communicate and adapt Chinese life, while only $22.6 \%$ think language is not a big problem in China. (Figure 9)

Table 8 is indicated the interaction of local Chinese with foreigners. In this research paper the main objective is highlight the important of Chinese language so therefore the interaction of Chinese people is very important role for developing the relationship with foreigners. 


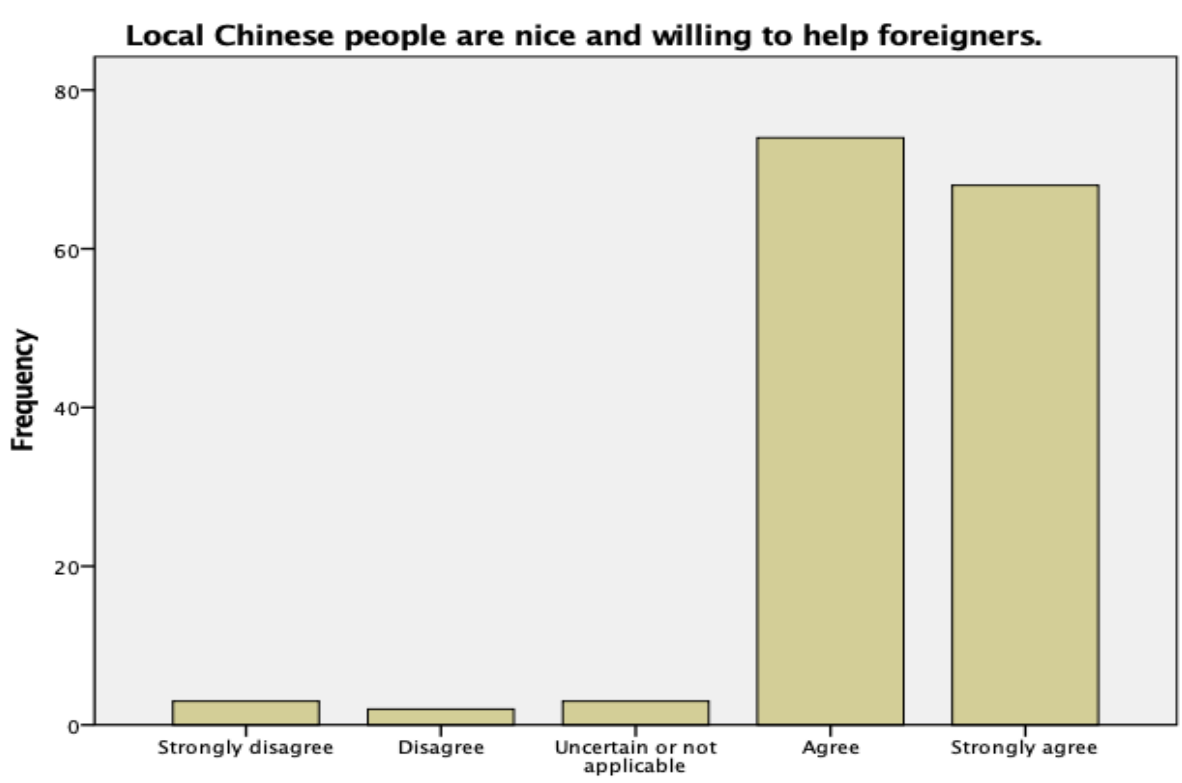

Local Chinese people are nice and willing to help foreigners.

Figure 10. Respondent view of question 8

The obtained results are indicated $49.3 \%$ positive response of African students who really appreciate and escalate the local people efforts. Figure 10

Table 9. Respondent view of question 9

\begin{tabular}{|c|c|c|c|c|}
\hline & Frequency & Percent & Valid Percent & Cumulative Percent \\
\hline \multirow{6}{*}{ Valid } & Strongly disagree & 50 & 33.3 & 33.3 \\
\hline & Disagree & 4 & 2.7 & 2.7 \\
\hline & Uncertain or not applicable & 35 & 23.3 & 23.3 \\
\hline & Agree & 25 & 16.7 & 16.7 \\
\hline & Strongly agree & 36 & 24.0 & 24.0 \\
\hline & Total & 150 & 100.0 & 100.0 \\
\hline
\end{tabular}

Table 9 is indicated the race and ethnicity of foreigner students in local community. As per some negative expects probably black foreigner might be looking wanted and mysterious personality in group of white people so therefore the local Chinese people some time bit confused and scare for any relation. 


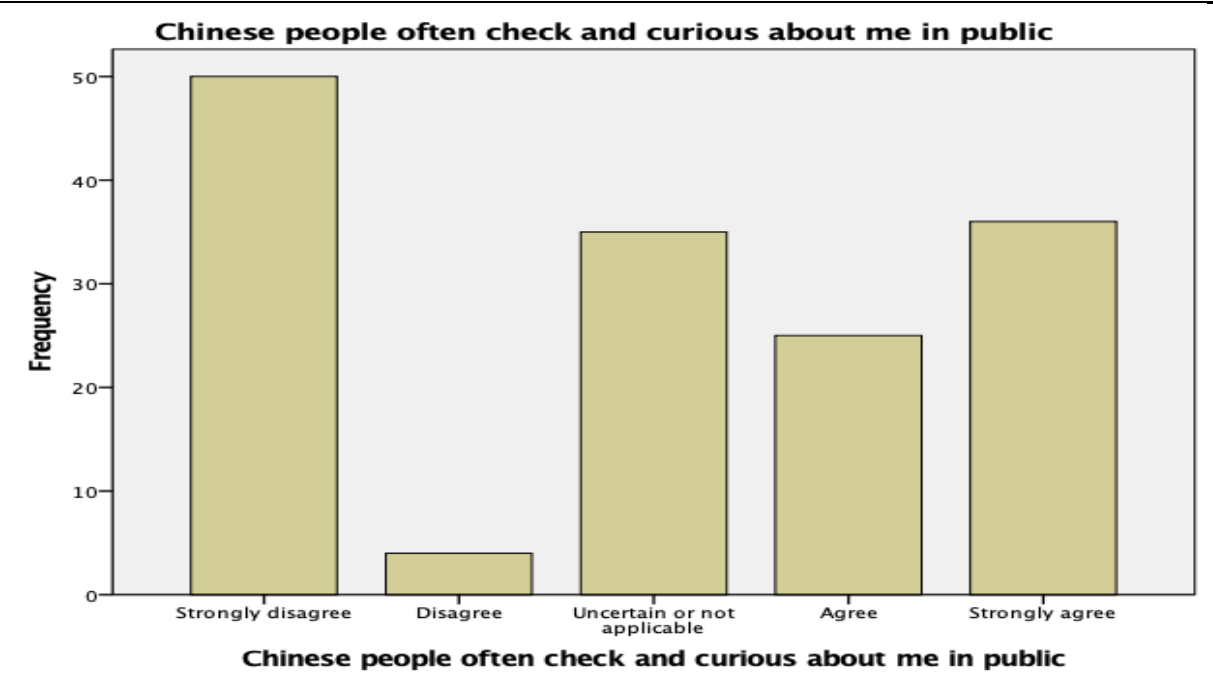

Figure 11. Respondent view of question 9

In this research paper the obtained results is also signified $33.3 \%$ students strongly agree that Chinese people often check and bit curious in public places and also irritating to convey any message to them. The barrier of communication is one expect but in other side the local Chines people also bit tangled and perplexed cause of ethnicity and their culture. Fig 11

Table 10. Respondent view of question 17

\begin{tabular}{|c|c|c|c|c|}
\hline & Frequency & Percent & Valid Percent & Cumulative Percent \\
\hline \multirow{6}{*}{ Valid } & Strongly disagree & 19 & 12.7 & 12.7 \\
\hline & Disagree & 20 & 13.3 & 13.3 \\
\hline & Uncertain or not applicable & 14 & 9.3 & 9.3 \\
\hline & Agree & 49 & 32.7 & 32.7 \\
\hline & Strongly agree & 48 & 32.0 & 32.0 \\
\hline & Total & 150 & 100.0 & 100.0 \\
\hline
\end{tabular}

Regarding question 9 the Table 10 is also indicated the ethnicity of black students and Chinese people perspective in different angles. The cross-culture interaction is mutual coordinate with exchange of relationship but the level of origin might create a barrier between this affiliation. The overall research results are analyzed that $32.7 \%$ Chinese people are conscious in region, ethnicity and cross-culture adoption. 
Most of Chinese people have a wrong perspective or Foreigners and

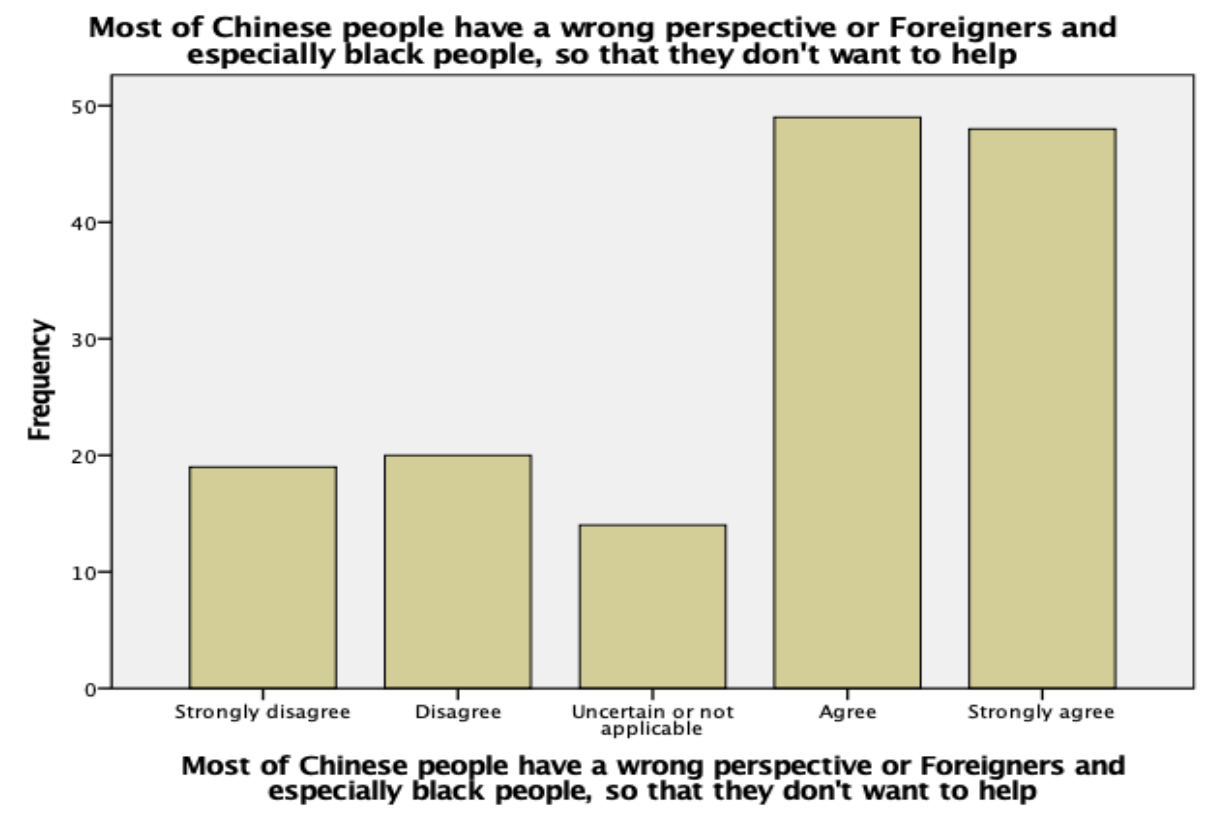

Figure 12. Respondent view of question 17

Furthermore, the well modified and bit cultured Chinese people are not facing any wrong perception against of black students and they are really promoting and appreciate the efforts in overall activities. Fig 12 As shown in Table 8-9, 94.6\% of responders think Chinese people are very friendly. However, more than $76 \%$ respondents cannot tolerate Chinese local people even students curious about African students in public.

Table 11. Respondent view of question 14

\begin{tabular}{|c|c|c|c|c|}
\hline & Frequency & Percent & Valid Percent & Cumulative Percent \\
\hline \multirow{6}{*}{ Valid } & Strongly disagree & 35 & 23.3 & 23.3 \\
\hline & Disagree & 54 & 36.0 & 36.0 \\
\hline & Uncertain or not applicable & 24 & 16.0 & 16.0 \\
\hline & Agree & 20 & 13.3 & 13.3 \\
\hline & Strongly agree & 17 & 11.3 & 11.3 \\
\hline & Total & 150 & 100.0 & 100.0 \\
\hline
\end{tabular}

Table 14 is indicated interaction of Chinese students with their friendly attitude. In the Chinese community, the friendship mean based on reliability and trust which held the relationship of two different people so therefore one expect is Chinese language and second ethnicity somehow create bit problem in relationship. 


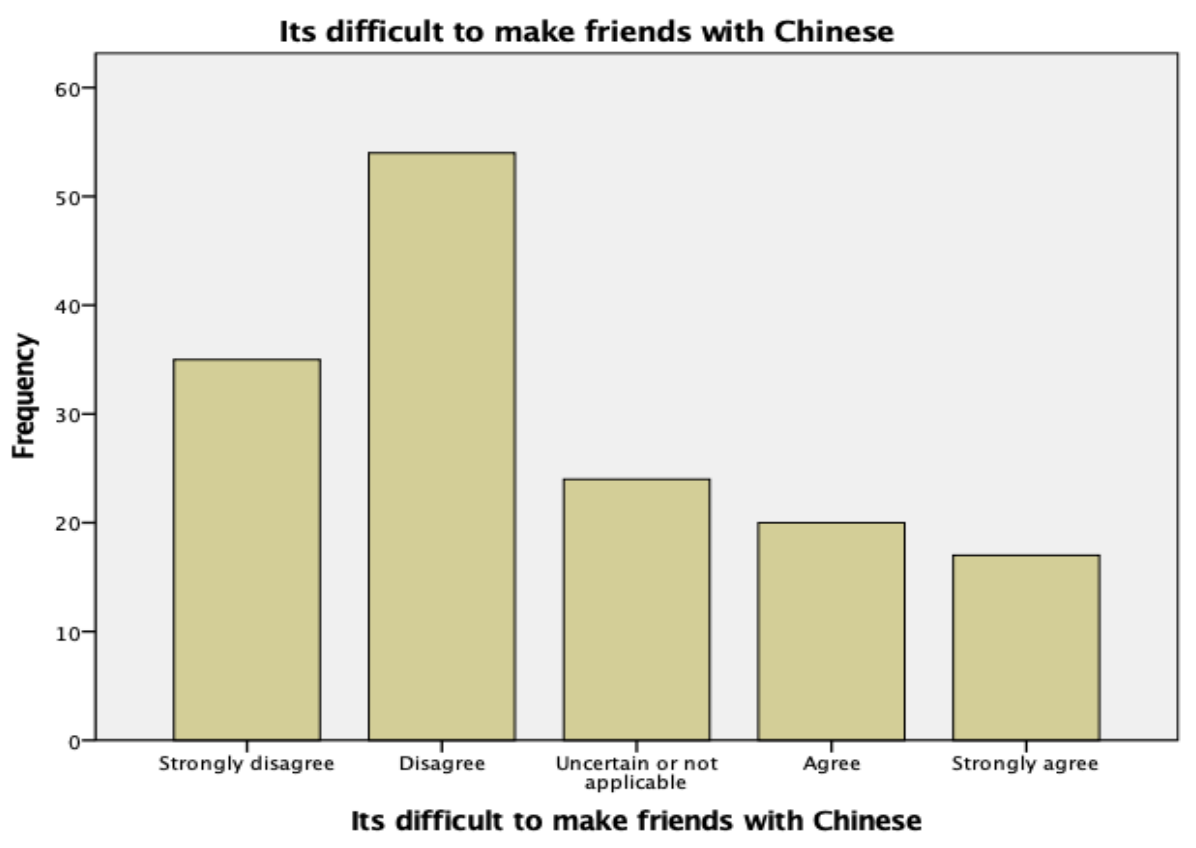

Figure 13. Respondent view of question 14

The obtained results are identified $13.3 \%$ students have faced bit difficulties in friendship in Chinese community and not easily adopt the whole friendly situation with entire remarks of good assertiveness and relation. Fig 13

Table 12. Respondent view of question 16

\begin{tabular}{|c|c|c|c|c|}
\hline & Frequency & Percent & Valid Percent & Cumulative Percent \\
\hline \multirow{6}{*}{ Valid } & Strongly disagree & 40 & 26.7 & 26.7 \\
\hline & Disagree & 93 & 62.0 & 62.0 \\
\hline & Uncertain or not applicable & 9 & 6.0 & 6.0 \\
\hline & Agree & 6 & 4.0 & 4.0 \\
\hline & Strongly agree & 2 & 1.3 & 1.3 \\
\hline & Total & 150 & 100.0 & 100.0 \\
\hline
\end{tabular}

Table 12 is indicated the coordination of Chinese community and society difference. The western culture is bit effected in eastern side and gradually change the mentality of according to their different regions but still it is affected on personality. The obtained results are analyzed that $4 \%$ students are not satisfy in Chinese gathering rather as others are feeling comfortable and relaxed in their community. 


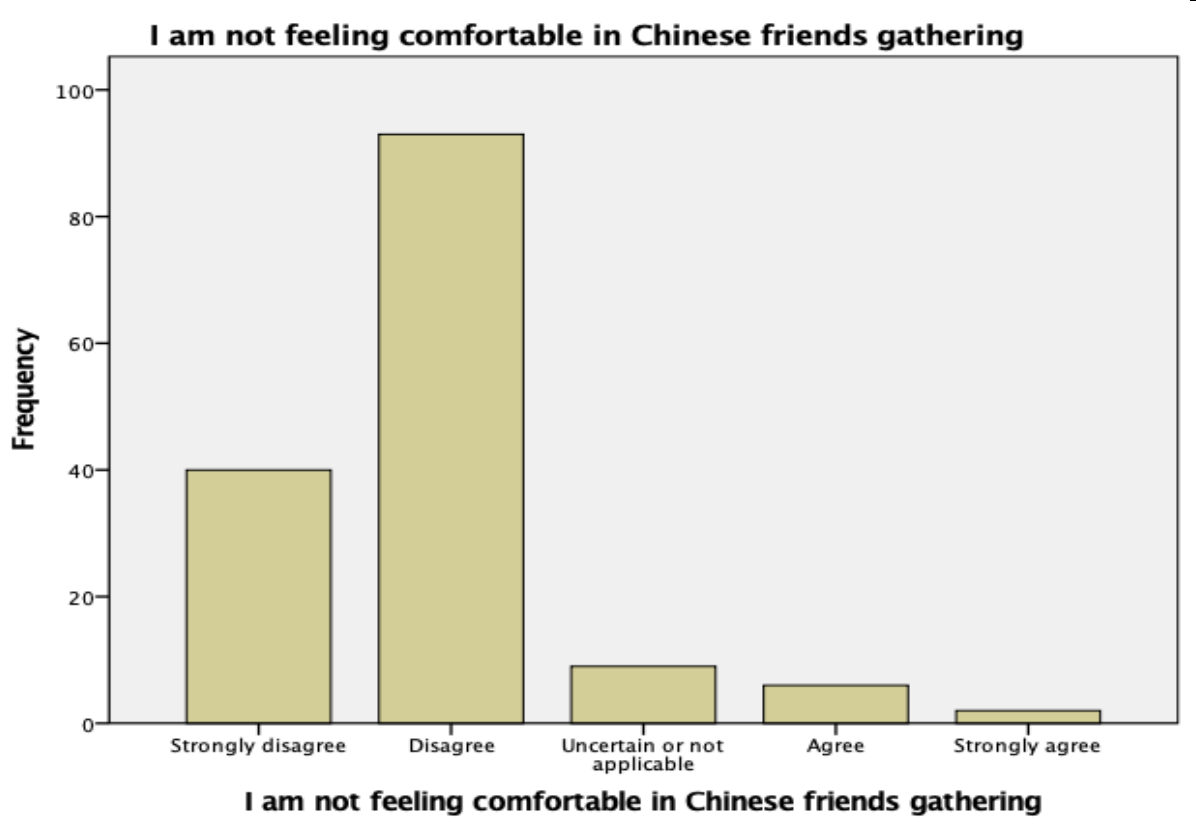

Figure 14. Respondent view of question 16

In Table 11-12, 59.3\% students consider that it is not difficult to make relation with Chinese friends, while in Table 12 is indicated $87.7 \%$ students deny that question because they feeling good in the Chinese gathering. Among the two comparisons, on the one hand, Chinese people are friendly that make foreigners feel well, on the other hand, because of different concept and values, there was a cultural in- adaptation. Furthermore, in the interview of the Chinese students, the interviewee responds that "We would like to help African students and willing to make friends with them, but there will misunderstand due to understanding of the different culture" Fig 14

Table 13. Respondent view of question 17

\begin{tabular}{|c|c|c|c|c|}
\hline & Frequency & Percent & Valid Percent & Cumulative Percent \\
\hline \multirow{6}{*}{ Valid } & Strongly disagree & 19 & 12.7 & 12.7 \\
\hline & Disagree & 20 & 13.3 & 13.3 \\
\hline & Uncertain or not applicable & 14 & 9.3 & 9.3 \\
\hline & Agree & 49 & 32.7 & 32.7 \\
\hline & Strongly agree & 48 & 32.0 & 32.0 \\
\hline & Total & 150 & 100.0 & 100.0 \\
\hline
\end{tabular}

Table 13 is indicated the Chinese people perception against on black students and bit conscious to deal anything cause their region and ethnicity. The obtained is specified that $32.7 \%$ Chinese 
don't want to make any coordination with black foreign students because the scare the situation and their behavior.

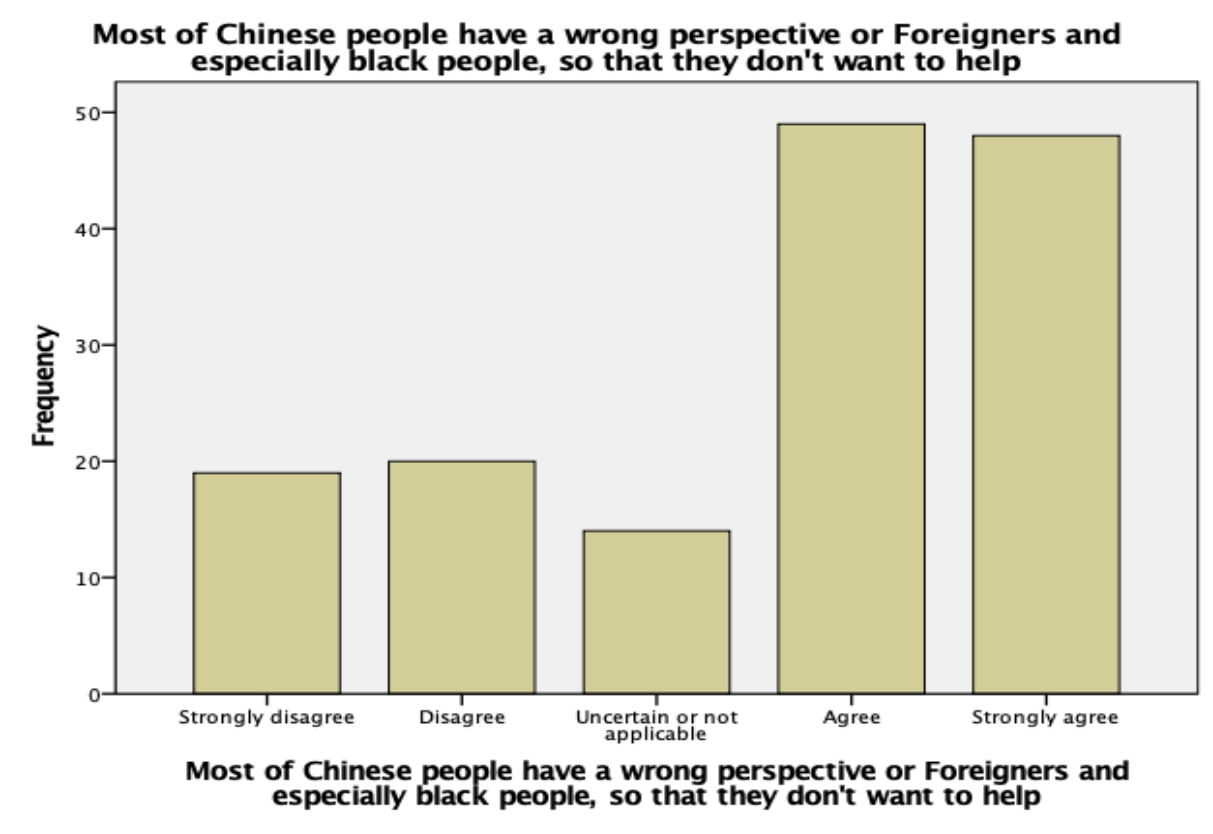

Figure 15. Respondent view of question 17

Figure 15 is indicated that $64.7 \%$ African students agree that Chinese people have a prejudice or stereotype, so that African student still feel very uncomfortable in life experience of China. And is also proved by interviewing with Chinese students who said it is really cannot accept African culture easily comparatively from Asian and Europe culture.

School management also has an important impact on foreigner cultural adaptation.

Table 14. Respondent view of question 5

\begin{tabular}{lllll}
\hline & Frequency & Percent & Valid Percent & Cumulative Percent \\
\hline Valid & Disagree & 26 & 17.3 & 17.3 \\
& Uncertain or not applicable & 33 & 22.0 & 22.0 \\
Agree & 7 & 4.7 & 4.7 \\
Strongly agree & 54 & 36.0 & 36.0 \\
Total & 30 & 20.0 & 20.0 \\
\hline
\end{tabular}

Table 14 is indicated that the comfortability issue of the Chinese students. The Chinese culture are truly based on their own perceptive and values. Therefore, the obtained result is indicated that $36 \%$ students are bit shy and feel hesitation during communication. 


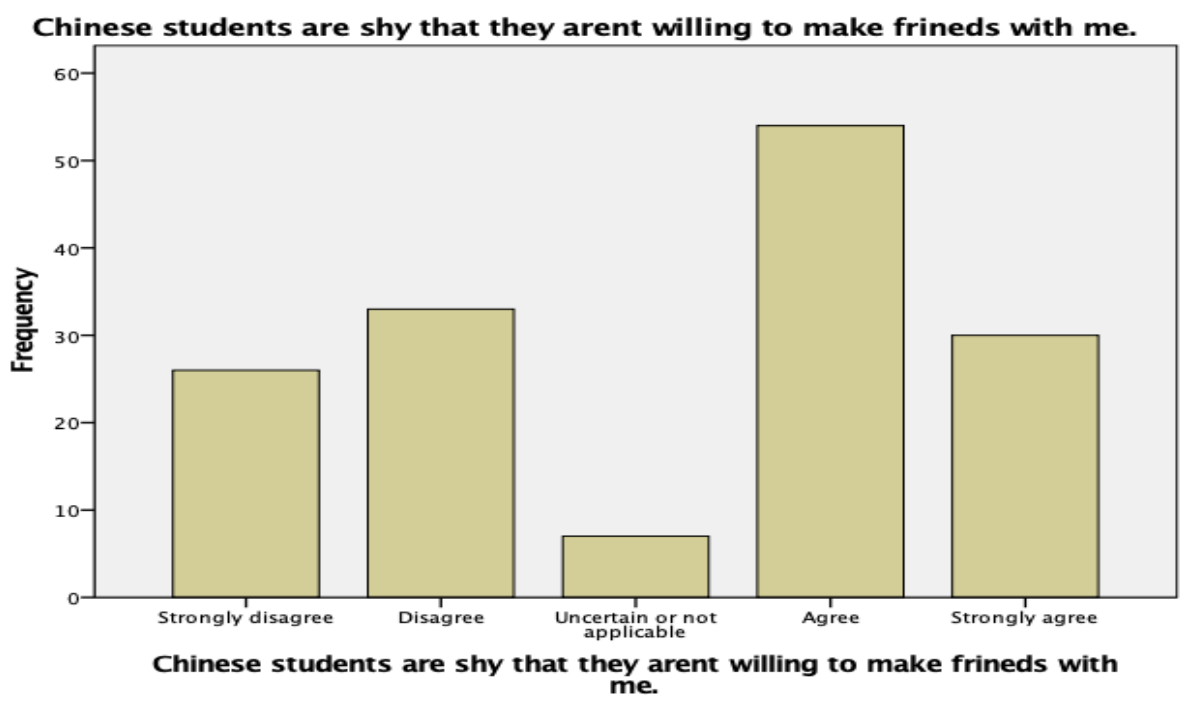

Figure 16. Respondent view of question 5

From the other expects the Chinese students feel comfort in their own society and held norms and value with their own Chinese friends therefore the relationship with foreigner is bit stranger.(Yushang, 2018). Figure 16

Table 15. Respondent view of question 7

\begin{tabular}{|c|c|c|c|c|}
\hline & Frequency & Percent & Valid Percent & Cumulative Percent \\
\hline \multirow{6}{*}{ Valid } & Strongly disagree & 22 & 14.7 & 14.7 \\
\hline & Disagree & 9 & 6.0 & 6.0 \\
\hline & Uncertain or not applicable & 1 & .7 & .7 \\
\hline & Agree & 94 & 62.7 & 62.7 \\
\hline & Strongly agree & 24 & 16.0 & 16.0 \\
\hline & Total & 150 & 100.0 & 100.0 \\
\hline
\end{tabular}

Table 15 is indicated the overseas education department policies and student's activities. The cross-culture adoption should need to diversify by the different activities and student's community. 
The university dont give many chances to comunicate and know Chinese

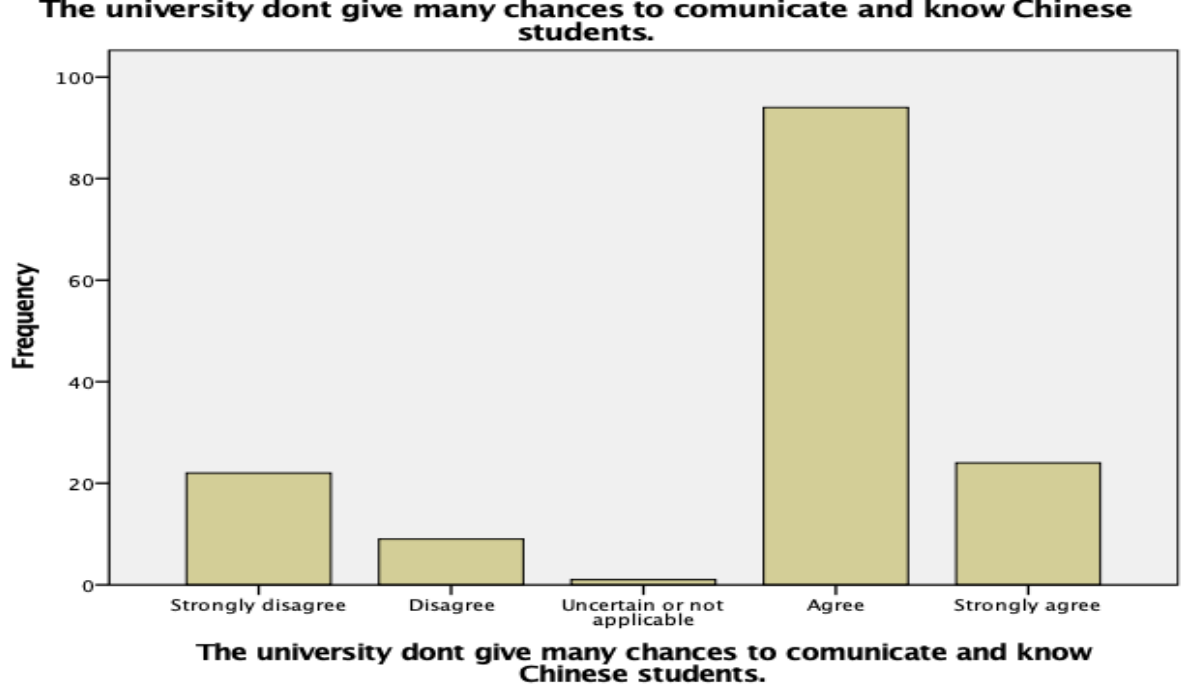

Figure 17. Respondent view of question 7

Therefore, the obtained results show $62.7 \%$ students are not satisfy from the university community because they are not giving many chances to promote the language and inter-social activities. Figure 17

Table 16. Respondent view of question 10

\begin{tabular}{|c|c|c|c|c|}
\hline & Frequency & Percent & Valid Percent & Cumulative Percent \\
\hline \multirow{6}{*}{ Valid } & Strongly disagree & 72 & 48.0 & 48.0 \\
\hline & Disagree & 14 & 9.3 & 9.3 \\
\hline & Uncertain or not applicable & 14 & 9.3 & 9.3 \\
\hline & Agree & 23 & 15.3 & 15.3 \\
\hline & Strongly agree & 27 & 18.0 & 18.0 \\
\hline & Total & 150 & 100.0 & 100.0 \\
\hline
\end{tabular}

Table 16 is indicated inter-social activities of the Chinese and foreign students. Over all lots of universities are really conscious in group activates and student's communities. Therefore, the foreign students are freely enjoying in the Chinese communities and enjoy in friendship. 


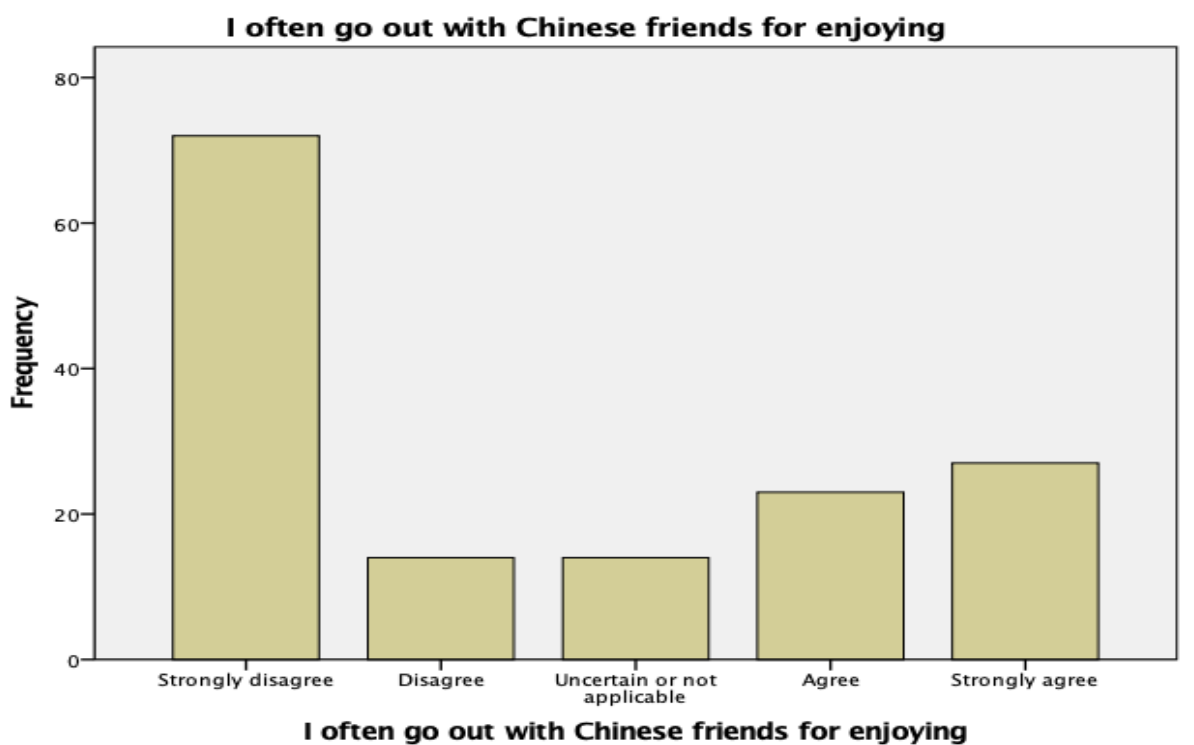

Figure 18. Respondent view of question 10

The obtained results also prove that $15.3 \%$ students are often enjoy in Chinese community and enjoy with them. And $48 \%$ students are bit confused and not really feel enjoy in Chinese gathering because the barrier of language have taken the big gap between them. Figure 18

Table 17. Respondent view of question 11

\begin{tabular}{|c|c|c|c|c|}
\hline & Frequency & Percent & Valid Percent & Cumulative Percent \\
\hline \multirow{6}{*}{ Valid } & Strongly disagree & 4 & 2.7 & 2.7 \\
\hline & Disagree & 3 & 2.0 & 2.0 \\
\hline & Uncertain or not applicable & 12 & 8.0 & 8.0 \\
\hline & Agree & 25 & 16.7 & 16.7 \\
\hline & Strongly agree & 106 & 70.7 & 70.7 \\
\hline & Total & 150 & 100.0 & 100.0 \\
\hline
\end{tabular}

Table 17 is indicated the philological issues of foreign students. Probably lots of the students not directly adopt with situation and cross culture issues so therefore they feel stress and aloneness. The obtained results are indicated $70.7 \%$ students are feeling comfortable when they involve their own people and culture. 


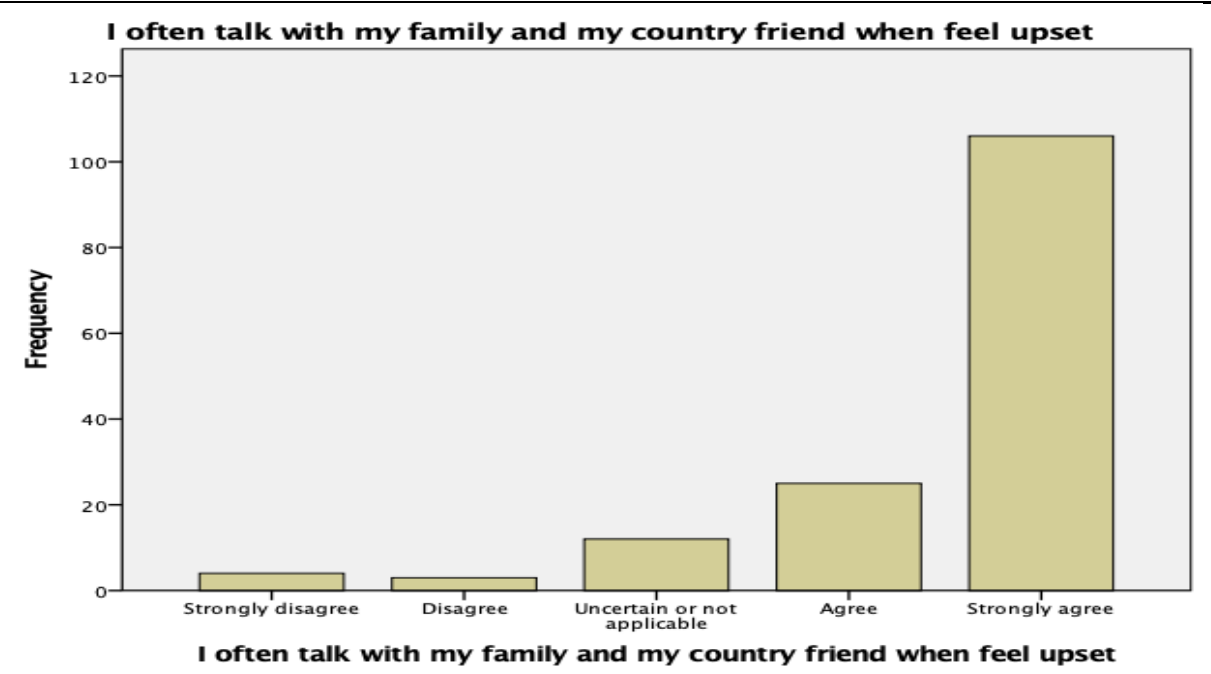

Figure 19. Respondent view of question 11

According to Table 16-17, it can be seen Foreign students don't have some Chinese friends even one. Even have, but never share the feeling with Chinese friends. The obtained results is indicated only $4.7 \%$ share and talk with Chinese, most people just tend to share feelings with the friends who come from own countries. Further, Table 14-15 is indicated that the reason, first university doesn't provide more chances to communicate with foreigners, which shown in Table 15. Second, as shown in Table 14, most of Foreign students think Chinese student are so shy make it difficult to make friends, however, from the interview of Chinese, except the students whose major is related English or Teaching Chinese as A Second Language, most students reply "We are also want to talk, but just lake of encouragement of oral English, and we don't have many chances to communicate with foreigners, we just avoid." Therefore, it indicates students need more chances to cooperation and exchange, whatever activity or academic exchange.

Table 18. Respondent view of question 13

\begin{tabular}{|c|c|c|c|c|}
\hline & Frequency & Percent & Valid Percent & Cumulative Percent \\
\hline \multirow{6}{*}{ Valid } & Strongly disagree & 10 & 6.7 & 6.7 \\
\hline & Disagree & 1 & .7 & .7 \\
\hline & $\begin{array}{l}\text { Uncertain } \\
\text { applicable }\end{array}$ & not 29 & 19.3 & 19.3 \\
\hline & Agree & 6 & 4.0 & 4.0 \\
\hline & Strongly agree & 104 & 69.3 & 69.3 \\
\hline & Total & 150 & 100.0 & 100.0 \\
\hline
\end{tabular}

Table 18 is indicated the obligation of student's jobs. The obtained results are analyzed that 
69.3\% students are completely satisfy that job is big issue in China if the language is cross because probably organization and universities are involved in their cross culture and norms so the except Chinese it is bit difficult to survive in China.

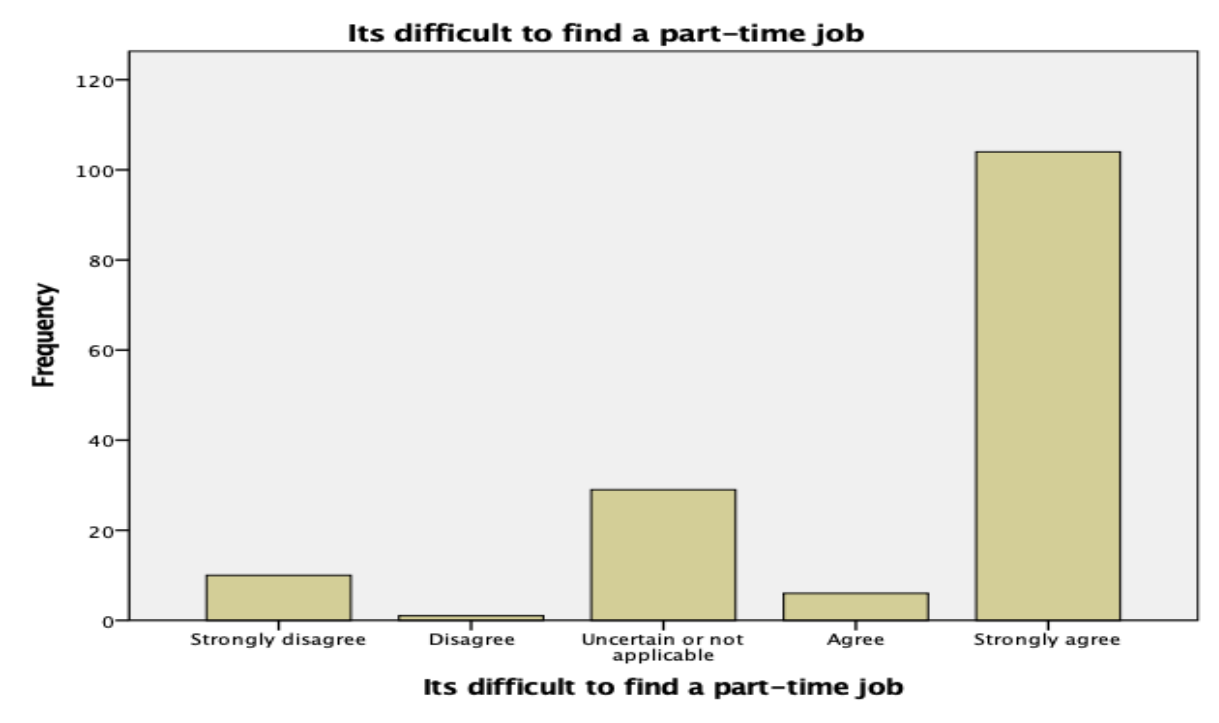

Figure 20. Respondent view of question 13

Furthermore, the obtained value is shows that around $70 \%$ students agree that it is very difficult to find a part-time job, African students have strong sense of independence, so that they will feel stressful for finding job which will make influence on adaptation of Chinese life. And through interview, international students' feedback that it will be better if universities can provide more chance to get a part-time job. Fig 20. So, we can know from these investigations school management will influence the adaptive capacity of Chinese culture. Table 19 is indicated the correlations of all questionnaire individual and shows the intercultural relationship among them. 


\section{Macrothink}

Table 19. Correlation

2019, Vol. 9, No. 4

\begin{tabular}{|c|c|c|c|c|c|c|c|c|c|c|c|c|c|c|c|c|c|}
\hline \multicolumn{18}{|c|}{ Correlations } \\
\hline & Q1 & Q2 & Q3 & Q4 & Q5 & Q6 & Q7 & Q8 & Q9 & Q10 & Q11 & Q12 & Q13 & Q14 & Q15 & Q16 & Q17 \\
\hline Q1 & 1.000 & & & & & & & & & & & & & & & & \\
\hline \multirow[t]{2}{*}{ Q2 } & $-.461^{* *}$ & 1.000 & & & & & & & & & & & & & & & \\
\hline & 0.000 & & & & & & & & & & & & & & & & \\
\hline \multirow[t]{2}{*}{ Q3 } & $.173^{*}$ & $-.349^{* *}$ & 1.000 & & & & & & & & & & & & & & \\
\hline & 0.017 & 0.000 & & & & & & & & & & & & & & & \\
\hline \multirow[t]{2}{*}{ Q4 } & $.256^{* *}$ & $-.251^{* *}$ & -0.004 & 1.000 & & & & & & & & & & & & & \\
\hline & 0.001 & 0.001 & 0.483 & & & & & & & & & & & & & & \\
\hline \multirow[t]{2}{*}{ Q5 } & $.229^{* *}$ & $-.307^{* *}$ & $.212^{* *}$ & $.403^{* *}$ & 1.000 & & & & & & & & & & & & \\
\hline & 0.002 & 0.000 & 0.005 & 0.000 & & & & & & & & & & & & & \\
\hline \multirow[t]{2}{*}{ Q6 } & -0.080 & $.222^{* *}$ & $-.213^{* *}$ & -0.123 & $-.272^{* *}$ & 1.000 & & & & & & & & & & & \\
\hline & 0.167 & 0.003 & 0.005 & 0.067 & 0.000 & & & & & & & & & & & & \\
\hline \multirow[t]{2}{*}{ Q7 } & $.260^{* *}$ & -0.101 & 0.096 & $.280^{* *}$ & $.332^{* *}$ & 0.016 & 1.000 & & & & & & & & & & \\
\hline & 0.001 & 0.110 & 0.122 & 0.000 & 0.000 & 0.421 & & & & & & & & & & & \\
\hline \multirow[t]{2}{*}{ Q8 } & 0.056 & 0.044 & $.221^{* *}$ & -0.041 & $-.159^{*}$ & $.186^{*}$ & 0.064 & 1.000 & & & & & & & & & \\
\hline & 0.250 & 0.295 & 0.003 & 0.309 & 0.026 & 0.011 & 0.219 & & & & & & & & & & \\
\hline Q9 & $.339^{* *}$ & 0.012 & 0.123 & -0.069 & 0.075 & $.491^{* *}$ & $.302^{* *}$ & $.301^{* *}$ & 1.000 & & & & & & & & \\
\hline
\end{tabular}




\begin{tabular}{|c|c|c|c|c|c|c|c|c|c|c|c|c|c|c|c|c|c|}
\hline & 0.000 & 0.441 & 0.067 & 0.202 & 0.180 & 0.000 & 0.000 & 0.000 & & & & & & & & & \\
\hline \multirow[t]{2}{*}{ Q10 } & 0.005 & $.243^{* *}$ & $-.429^{* *}$ & $-.175^{*}$ & $-.619^{* *}$ & $.499^{* *}$ & $-.271^{* *}$ & 0.109 & -0.007 & 1.000 & & & & & & & \\
\hline & 0.476 & 0.001 & 0.000 & 0.016 & 0.000 & 0.000 & 0.000 & 0.093 & 0.465 & & & & & & & & \\
\hline \multirow[t]{2}{*}{ Q11 } & -0.083 & -0.098 & -0.068 & 0.001 & $-.145^{*}$ & -0.050 & $-.244^{* *}$ & $.261^{* *}$ & $-.218^{* * *}$ & $.220^{* *}$ & 1.000 & & & & & & \\
\hline & 0.157 & 0.116 & 0.206 & 0.494 & 0.038 & 0.272 & 0.001 & 0.001 & 0.004 & 0.003 & & & & & & & \\
\hline \multirow[t]{2}{*}{ Q12 } & $-.355^{* *}$ & 0.129 & 0.041 & $-.172^{*}$ & $-.264^{* *}$ & 0.020 & $-.324^{* *}$ & 0.047 & $-.324^{* *}$ & $.246^{* *}$ & $.216^{* *}$ & 1.000 & & & & & \\
\hline & 0.000 & 0.058 & 0.309 & 0.018 & 0.001 & 0.406 & 0.000 & 0.283 & 0.000 & 0.001 & 0.004 & & & & & & \\
\hline \multirow[t]{2}{*}{ Q13 } & $-.349^{* *}$ & 0.087 & $-.158^{*}$ & $-.191^{* *}$ & $-.204^{* *}$ & 0.094 & -0.132 & 0.081 & 0.053 & 0.111 & $.140^{*}$ & $.412^{* *}$ & 1.000 & & & & \\
\hline & 0.000 & 0.144 & 0.027 & 0.010 & 0.006 & 0.127 & 0.054 & 0.163 & 0.260 & 0.087 & 0.043 & 0.000 & & & & & \\
\hline \multirow[t]{2}{*}{ Q14 } & $.192^{* *}$ & $-.144^{*}$ & -0.105 & 0.077 & $.419^{* *}$ & $.158^{*}$ & $.304^{* *}$ & -0.045 & $.514^{* *}$ & $-.256^{* *}$ & $-.216^{* *}$ & $-.268^{* *}$ & $.152^{*}$ & 1.000 & & & \\
\hline & 0.009 & 0.040 & 0.101 & 0.174 & 0.000 & 0.026 & 0.000 & 0.290 & 0.000 & 0.001 & 0.004 & 0.000 & 0.032 & & & & \\
\hline \multirow[t]{2}{*}{ Q15 } & $-.177^{*}$ & 0.072 & $-.324^{* *}$ & 0.079 & $.313^{* *}$ & $-.149^{*}$ & -0.097 & $-.197^{* *}$ & $-.481^{* *}$ & 0.072 & $.279^{* *}$ & $.425^{\text {*** }}$ & $.237^{* *}$ & -0.024 & 1.000 & & \\
\hline & 0.015 & 0.192 & 0.000 & 0.168 & 0.000 & 0.034 & 0.119 & 0.008 & 0.000 & 0.191 & 0.000 & 0.000 & 0.002 & 0.384 & & & \\
\hline \multirow[t]{2}{*}{ Q16 } & -0.031 & 0.035 & -0.102 & $-.321^{* *}$ & -0.051 & 0.074 & -0.009 & -0.129 & -0.036 & 0.112 & $-.228^{* *}$ & $.206^{* *}$ & $.351^{* *}$ & $.240^{* * *}$ & $.281^{* *}$ & 1.000 & \\
\hline & 0.353 & 0.336 & 0.107 & 0.000 & 0.267 & 0.183 & 0.457 & 0.057 & 0.330 & 0.086 & 0.003 & 0.006 & 0.000 & 0.002 & 0.000 & & \\
\hline \multirow[t]{2}{*}{ Q17 } & -0.036 & -0.113 & -0.121 & $.339^{* *}$ & $.420^{* *}$ & -0.048 & 0.048 & $-.203^{* *}$ & $-.232^{* *}$ & $-.183^{*}$ & -0.068 & -0.030 & $-.189^{*}$ & 0.111 & $.316^{* *}$ & -0.071 & 1.000 \\
\hline & 0.331 & 0.085 & 0.070 & 0.000 & 0.000 & 0.279 & 0.281 & 0.006 & 0.002 & 0.013 & 0.203 & 0.358 & 0.010 & 0.089 & 0.000 & 0.193 & \\
\hline
\end{tabular}

**. Correlation is significant at the 0.01 level (1-tailed). *. Correlation is significant at the 0.05 level (1-tailed). c. List wise $\mathrm{N}$ 


\subsection{Interviews With Chinese Students}

The interview has been conducted from 15 Chinese students and taking information regarding specify topics likewise (a) will you be unconfident when talk in English but still want to talk with foreigners? (b) Do you agree that you just prefer Asia and European American cultural? (c) How do you think of African students. The obtained results are indicated the different major students have different attitude of African students. The majors related Teaching Chinese As a Second Language students have a more positive attitude; they are willing to make friends and be confident to speak in English. Second Chinese students want to talk with foreigners, but due to lack of confidence the level of English level is not good and clear. Moreover, they don't have a little more chance to make friends with foreigners. Such as the lack of activities between Chinese and African students. Third, due to race and ethnicity the most of Chinese student don't think the overall quality of African student, which is admirable and commending so without that expect they often try to keep themselves away.

\section{Conclusion and Recommendation}

\subsection{Conclusion}

This study provides insight into these consequences. Above findings shows that there is a close relation between the degree of adaptation and living condition, Chinese language and cultural conception.

1) The living condition has an effect on the Foreign students' adaption in China and it can be seen African students have different evaluations they are satisfied with the room condition compare with their own country. However, still there are a lot of student need more privacy, maybe cause of African have a strong individualistic concept. On the contrary, A large of people would like to share one room with same group, which will release stress and loneliness.

2) Chinese language is one of the most important factors which influence cultural adaptation of African students in China and most of the international students have command on the Chinese language and communicate with local people. However, there is no enough chance to talk with Chinese students. The qualitative analysis is indicated that Chinese students view likewise, "we want to talk but lake of chance" That is the reason why this study talk about school management which should create more chance for both.

3) The different cultural concept is also exerting an effect on adaption in China life. the problem is that cultural difference brings a big issue in communicate with Chinese. Especially for African, Chinese are very friendly but can't tolerate they curiosity attitude. Moreover, most of foreigners think it is not difficult to make friend with Chinese, and they also feel good gathering with Chinese. However, the fact shows they don't have many Chinese even one, even have, but not enjoy and share with them. According to qualitative view the Chinese is consistently to show that to accept western culture than African culture, there is a kind of prejudice.

4) International students are also facing a problem is the pressure of finance. Most of students 
think it is very difficult to find a part-time job in China which make them feel more stress, In the China, some major foreign students don't have scholarship, so therefore try to find different opportunities to survive but under legal legislation its restricted for foreign students.

\subsection{Recommendations}

1) This huge burden of mental and substance of African students in China, call for attention of University leader and managers. Try to improve university management. (a) Create more chances for foreign students to get a part-time job so that can release their economic burden. (b) Improve and perfect the curriculum, as far as possible for students of different majors to open sino-foreign cultural exchange courses to let them know each other culture. Especially about African culture, and Chinese students can have a correct understanding of African culture. (c) It should be better if universities can try to organize diverse cultural activities, therefore, they can show self-culture and enhance cultural confidence, on the other hand, Whatever Chinese students or African students, all of them can have chances to communicate and make friends, form a big cultural family.

2) Most significantly, individual effort is important to adapt Chinese culture well. First, African students should try to learn Chinese well with existing conditions, even though there are no Chinese friends, they can practice in class or after class. Second, African students should keep confident to talk politely, participate in school or social organization of cultural activities accurately, also try to understand Chinese culture and Chinese character to avoid culture misunderstanding.

\section{Acknowledgements}

I really appreciate the efforts of my colleague who really guide me with all numeric and statistically tool. Initially it bit difficult for me but I really thanks to my supervisor and teachers as well as my intimate friend who hold my hands in all hurdles of research and gave me proper supervision and I have no words to identify his faith and loyalty. Furthermore, I deeply thanks to my beloved parents and mainly my father support and encouragement.

\section{References}

Berry, J. W. (2005). Acculturation: Living successfully in two cultures. International Journal of Intercultural Relations, 29, 697-712.https://doi.org/10.1016/j.ijintrel.2005.07.013

Bo, N. A. C. B. P. S. (2015). Factors in the cross-cultural adaptation of African students in Chinese universities. Journal of Research in International Education, 14(2), 98-113. https://doi.org/10.1177/1475240915592107

Furnham, A., \& Bochner, S. (1986). Culture shock: Psychological reactions to unfamiliar environment. London: Methuen.

Glass, C. R., Gómez, E., \& Urzua, A. (2014). Recreation, intercultural friendship, and international students' adaptation to college by region of origin. International Journal of Intercultural Relations, 42, 104-117. https://doi.org/10.1016/j.ijintrel.2014.05.007 
Hvistendahl, M. (2008). China moves up to fifth as importer of students. Chronicle of higher education, 55(4), A21-A22.

Kim, Y. Y. (2001). Becoming intercultural: An integrative theory of communication and cross-cultural adaptation. London: Sage.

Kim. (2012). Cross-Cultural Adaptation. Cross-Cultural Adaptation. Encyclopedia of Human Behavior. https://doi.org/10.1016/B978-0-12-375000-6.00115-4

Kong, Y., \& Khan, R. (2019). To examine environmental pollution by economic growth and their impact in an environmental Kuznets curve (EKC) among developed and developing countries. PloS one, 14(3). PMid: 30913276 PMCid: PMC6435177. https://doi.org/10.1371/journal.pone.0209532

Miglietta, A., \& Tartaglia, S. (2009). The influence of length of stay, linguistic competence, and media exposure in immigrants' adaptation. Cross-Cultural Research, 43(1), 46-61.

Peng, R. Z., \& Wu, W. P. (2019). Measuring communication patterns and intercultural transformation of international students in cross-cultural adaptation. International Journal of Intercultural Relations, 70, 78-88. https://doi.org/10.1016/j.ijintrel.2019.03.004

Redfield, R., Linton, R., \& Herskovits, M. J. (1936). Memorandum for the study of $\begin{array}{llll}\text { acculturation. } & \text { American } & \text { anthropologist, } & \text { 149-152. }\end{array}$ https://doi.org/10.1525/aa.1936.38.1.02a00330

Rienties, B., Nanclares, N. H., Jindal-Snape, D., \& Alcott, P. (2013). The role of cultural background and team divisions in developing social learning relations in the classroom. Journal of Studies in International Education, 17(4), 332-353.

Sarmiento, A. V., Pérez, M. V., Bustos, C., Hidalgo, J. P., \& del Solar, J. I. V. (2019). Inclusion profile of theoretical frameworks on the study of sociocultural adaptation of international university students. International Journal of Intercultural Relations, 70, 19-41. https://doi.org/10.1016/j.ijintrel.2019.02.004

Wang, H. (2015). Social network sites and international students' cross-cultural adaptation. Computers in Human Behavior, 49, 400-411.https://doi.org/10.1016/j.chb.2015.03.041

Yang, R. P. J., Noels, K. A., \& Saumure, K. D. (2006). Multiple routes to cross-cultural adaptation for international students: Mapping the paths between self-construals, English language confidence, and adjustment. International Journal of Intercultural Relations, 30(4), 487-506. https://doi.org/10.1016/j.ijintrel.2005.11.010

Yushang, K. (2018). Willpower of Retentive Factors in Job Level and Recital Human Resource Management in Project. International Journal of Learning and Development. https://doi.org/10.5296/ijld.v8i1.12173

YY, G. W. a. K. (2003). Communicating with Strangers: An Approach to Intercultural Communication (Vol. 4). New York: McGraw-Hill.

孙乐芩, 冯江平, 林莉, \& 黄篵杉. (2009). 在华外国留学生的文化适应现状调查及建议. 


\section{Macrothink}

International Journal of Learning and Development ISSN 2164-4063

语言教学与研究, (1), 41-48.

张静园. (1998). 外国留学生在华生活的心理适应问题和对策. 中国高教研究, 5, 46-47. https://doi.org/10.16298/j.cnki.1004-3667.1998.05.016

\section{Copyright Disclaimer}

Copyright for this article is retained by the author(s), with first publication rights granted to the journal.

This is an open-access article distributed under the terms and conditions of the Creative Commons Attribution license (http://creativecommons.org/licenses/by/4.0/). 